Preprints of the

Max Planck Institute for

Research on Collective Goods

Bonn 2008/37

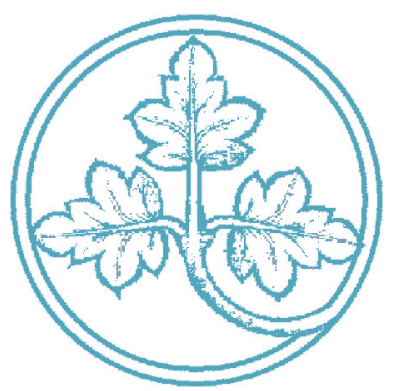

Reciprocity and status in a virtual field experiment

Andreas Nicklisch /

Tobias Salz

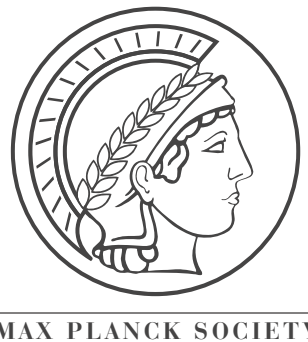




\section{Reciprocity and status in a virtual field experiment}

Andreas Nicklisch / Tobias Salz

October 2008 


\title{
Reciprocity and status in a virtual field experiment ${ }^{\dagger}$
}

\author{
Andreas Nicklisch* / Tobias Salz ${ }^{\ddagger}$
}

\begin{abstract}
This article reports on a field study that has been conducted in the online computer game World of Warcraft. In a basic labor situation a principal gives an upfront wage to an agent (who is unaware that he is participating in an experiment) and asks him to conduct a real-effort task. The unique characteristic of the virtual world allows us to control for agents' abilities to perform the task and to manipulate the principal's social status. Confirming gift exchange theory, generous wages indeed increase agents' efforts, even controlling for agents' abilities, while the principals' social status influences effort provision probability substantially. We interpret this result such that agents assess the kindness of the wages with respect to the expected principals' wealth.
\end{abstract}

Keywords: Field experiment, gift-exchange, reciprocity, status, virtual world

JEL: C88, C93, D63

$\dagger \quad$ We are grateful for helpful comments and suggestions by Christoph Engel, Sebastian Kube, Hans-Theo Normann, and, especially, Bernd Irlenbusch. The paper has also benefited from comments by participants of the Tiber workshop 2008 in Tilburg, the ESA conference 2008 in Lyon, and the IZA workshop in Bonn, 2008. We thank Andreas Staffeldt, Matthias Cremerius and Jörg Osenberg for assistíng us in collecting the data.

* $\quad$ Max Planck Institute for Research on Collective Goods; Kurt-Schumacher-Strasse 10, D-53113 Bonn, Germany; email nicklisch@,coll.mpg.de

$\$ \quad$ Max Planck Institute for Research on Collective Goods and University of Bonn; Kurt-Schumacher-Strasse 10, D-53113 Bonn, Germany; email salz@,coll.mpg.de 


\section{Introduction}

Reciprocity has proven to be an essential determinant for human behavior. ${ }^{1}$ Humans exhibit a behavioral tendency to respond kindly to others by whom they were treated kindly. There is profound evidence showing the importance of reciprocity for human interactions in all kinds of economic contexts. Principals induce agents to provide costly effort that is not contractually enforceable by providing generous wages upfront; participants contribute voluntarily to public good games; and they are willing to sacrifice their own payoffs to change the payoffs of others in bargaining games. ${ }^{2}$

We present a first field experiment on reciprocity in a real-effort employment relation, using an online game as the experimental platform. Recently, experimental economists have intensively discussed the potentials of online games which visually mimic complex physical space for research on socially embedded human interactions (Bainbridge, 2007, Bloomfield, 2007). ${ }^{3}$ We conduct a gift exchange experiment, testing the role of reciprocity for employment relations in the virtual world ${ }^{4}$ World of Warcraft (henceforth WoW). ${ }^{5}$ The unique characteristic of WoW allows us to control for abilities to perform the task and to manipulate unambiguously the social context within which the interaction takes place. The experimenter plays the role of the principal. Participants who are unaware that they are engaged in an experiment are offered a wage for performing a real-effort task; particularly, they were recruited to fish for us in the virtual world.

There is a longstanding economic literature stressing the influence of reciprocity for principalagent relations (e.g., Akerlof, 1982, Akerlof \& Yellen, 1990). Following the seminal experimental setup by Fehr et al. (1993), the majority of empirical results are collected in laboratory experiments. Recently, experimentalists have started to test employment relations in more realistic settings. To give one example, real effort experiments analyze performance when agents have to work on real effort tasks (e.g., cracking walnuts, Fahr \& Irlenbusch, 2000, or solving cognitive tasks, van Dijk et al., 2001, Gneezy, 2003). Recognizing the importance of social structures for economic outcomes, ${ }^{6}$ other authors have started to analyze the effect of reciprocity for labor markets "in the field"7 (e.g., Al-Ubaydli et al, 2006, Falk \& Ichino, 2006, Gneezy \& List, 2006, Fehr \& Götte, 2007). Both branches of research were able to identify reciprocity as vital for employment relations. However, both types face problems that are due to the specific setting. For instance, while participating in a real effort experiment, agents know that their actions are observed by the experimenter. On the other hand, field experiments provide very limited control

1 For instance, Gouldner (1960), Fehr \& Gächter (2000), and Gintis (2000).

2 E.g., see Isaac et al. (1985) and Fischbacher et al. (2001) for public goods games, Güth et al. (1982) for ultimatum bargaining games, and Fehr et al. (1993) for the gift-exchange games. For a survey on social preferences and, particularly, on reciprocity, see Fehr \& Schmidt (2006).

3 There are quite a number of experiments in virtual worlds where participants are aware that they are participating in an experiment (e.g., Chesney et al., 2007, Castranova, 2008, Fiedler, Haruvy \& Li, 2008).

Castranova (2001) establishes this terminology.

WoW has been already subject to intensive research on social networks (e.g., Williams, 2006).

Granovetter $(1985,2005)$ introduces the term "social embeddedness" in order to illustrate the interdependencies between economic activities and social structure.

7 According to the taxonomy of Harrison and List (2004), one refers to "natural field experiments". 
over agents' skills for performing the task. ${ }^{8}$ Our experimental setup, that is, a field experiment conducted in a virtual world, is halfway between the two traditional settings. Like in a field experiment, it allows us to observe the employment relation as socially embedded, while, similar to a laboratory experiment, we keep substantial control over the task (details are described below).

We will test for the effect of reciprocity on employment relations along two treatment variations and with respect to two target dimensions. The first treatment variation concerns two different wage rates. This variation will allow us to analyze whether different wage rates attract agents with different task performance skills. If we find for higher wages systematically higher abilities to perform the task, this could explain higher reciprocation rates simply by higher productivity. However, if we find higher reciprocation rates even controlling for performance skills, this indicates gift exchanging behavior.

We contrast the wage variation with a variation in the social context within which the employment relation is formed. The reason for this is that former field experiments have shown that the assessment of wage rates' kindness needs additional information concerning the surplus of effort provision (e.g., Hennig-Schmidt et al., 2008). However, this information is rarely provided in real employment relations. We claim that the principal's status and, consequently, expectations with respect to the wealth shape the agents' valuation of wage rates. Therefore, the status of the principal in the experiment systematically varies. For this purpose, WoW offers a unique and unambiguous scale for social status and prestige, which is immediately displayed once players interact. The status level increases if players accomplish tasks and fights; high levels signal high experience, reputation, and financial resources. In the gift exchange game, we either have a high status principal or a low status principal. This will allow us to analyze whether the perception of a generous versus a reasonable wage depends on the principal's social status. One could argue that reasonable wage offers made by high status principals disappoint agents' expectations, while the same wage offers made by low status principals are perceived as considerable according to the principal's expected wealth. This implies that a wage offer by a low status player leads to higher reciprocation rates than the high status principal's offer. We will discuss this argument in more detail in section three.

With respect to the target values of our study, we provide an important modification to previous gift exchange field experiments (e.g., Kube et al., 2007). We pay agents upfront, so that shirking is a viable alternative for agents. Therefore, the agents' decision is two-fold, such that they first have to decide on whether to provide effort or not, and then on how much effort is provided. Psychologists stress the difference between the decision whether to act and the decision about how much to act (e.g., Ajzen, 1991). Hence, we will analyze the results both with respect to the probability that agents provide effort and with respect to the extent to which effort is provided.

The results indicate two main findings: first, in our setting where agents are paid upfront, we find gift exchange. Even if we control for performance skills, we find higher reciprocation rates for

8 For instance, Falk (2007) tests the effect of small gifts which were enclosed to solicitation letters knowing little about subjects' total annual donations for charity purposes. 
high wages. This result is found for the probability to provide effort and the extent to which effort is provided. However, social status crucially (and only) matters for the decision whether to provide effort or not. We observe some kind of low-status advantage for principals. That is, for low-status principals, the provision probability increases substantially, even over-compensating the wage rate effect for low-status principals offering low wages.

The remaining article is organized as follows: section two reports the experimental setup, while section three discusses research hypotheses. Section four reports the experimental results and section five concludes.

\section{Method}

The experiments are conducted in World of Warcraft, a massively multiplayer online roleplaying game, in October and November 2007. Players connect via their personal computer running special software with servers that interchange the information between users over the internet. The software simulates a large, complex, three-dimensional environment filled with artificial objects through which the player can subjectively walk, swim, or fly. Players are represented by animated characters, avatars, belonging to two opposing fractions of many races and genders (further details are described in Bainbridge, 2007).

Currently, WoW is one of the largest virtual worlds with 10 million subscribers (Blizzard, 2008). Players typically are male adults with a wide variety of occupations and demographic characteristics. Mean age is 26.5, ranging from $11-68 .{ }^{9} \mathrm{WoW}$ is organized such that subscribers are grouped on several identical servers; there is almost no interaction between different servers. ${ }^{10}$ For instance, there are approximately 40 German-speaking servers of 6,000 to 10,000 players, each living in identical, but separate environments. ${ }^{11}$ Each treatment condition of our experiment is conducted on a new German-speaking server so that new participants are unfamiliar about other treatment variations. All sessions are conducted in the evening of a weekend day.

There are several communication channels through which players chat in WoW. For the purpose of our experiment, we use the whispering channel, which allows one-to-one communication where no other player can listen. For each player in the field of view, name and level appear by clicking on him, while double clicking activates the chat.

There is no legal enforcement system in WoW. Players can simply ignore the existence of another person by activating the "ignore" option for that player. Hence, providing effort demonstrates agents' reciprocity, although we cannot exclude the unlikely possibility that they subcontract the task.

$9 \quad$ Further details can be found in the exploratory study by Yee (2006).

10 Transferring an avatar between different servers is costly and has to be requested from the operator of WoW.

11 Initially, avatars are assigned to a random server, unless players deliberately ask for a specific server. 
WoW has his own currency, gold coins, which is convertible into real-world currencies in online auction platforms like eBay. The exchange rate at the time of the experiment is about 2.1 euro cents for one gold coin. ${ }^{12}$

Most importantly for our study, WoW is a world with a distinct hierarchical order, the status level. For the accomplishment of tasks, players receive experience points which lead to an upgrade in their levels. ${ }^{13}$ The level is the unique and unambiguous scale for social status and prestige in WoW, which is immediately displayed next to the unique name of the avatar, once players interact. ${ }^{14}$ WoW's status system contains seventy levels at the time of the experiment. A freshman starts at level one; avatars of level ten or below are usually considered as "newbies". Players with a level lower than thirty are called low-level avatars. For the currently highest level, seventy, one needs on average several months of pure play-time in $\mathrm{WoW},{ }^{15}$ so that high-status levels indicate massive investments in terms of play-time, signaling high dedication to the game as well as high financial resources in the game.

For the experiment, subjects were randomly approached on the streets around the market square of a particular city and were asked whether they could assist us. Participants were offered gold coins in exchange for providing effort, that is, to fish at a certain lake for thirty minutes and to return the complete catch. We instruct clearly that this task will not be repeated. Further questions concerning the purpose of fish were not answered. Participants were required to send us their entire catch within 24 hours via the virtual WoW mailing system, ${ }^{16}$ so that no further communication was needed once the agent had received the money.

Depending on the treatment condition, we played either a female level 10 warriors (L) or male level 49/50 warriors $(\mathrm{H})$ as the principal. In different treatments, participants are offered 4 or 12 gold coins in advance for 30 minutes' fishing in the canal of the city. Four gold coins is a reasonable salary for thirty minutes' work, ${ }^{17}$ whereas 12 gold coins is, in terms of WoW, a generous salary. Thus we have four treatment conditions which we experimentally test. In total, 103 participants were recruited for the experiment, 25 participants in the H/12, 27 in the H/4, 26 in the $\mathrm{L} / 12$, and 25 in the $\mathrm{L} / 4$ condition.

Figure 1 shows players fishing in WoW. Fishing is a "real" effort task that requires the physical attention of players: players throw the fishing hook into the water; within a time-frame of five to twenty seconds, the float, while moving on the surface of the water, starts wiggling for one second; only when one double-clicks on the float in that moment might players catch a fish (one

12 Notice that the most expensive virtual object in WoW at the time of experiment costs 5000 gold coins.

13 Players' status level cannot decrease; there is no depreciation due to inactivity or socially inappropriate behavior.

14 Other characteristics like gender or profession are less pronounced; for instance, professions have to be looked up separately.

15 For details, see Blizzard's homepages http://www.worldofwarcraft.com

16 The mailing system allows the transportation of all items in WoW.

17 For 30 minutes of work in WoW, 4 gold coins are typically charged. Subscribers to WoW have to pay a fee of thirteen euro for thirty-day access to the server (and, therefore, to the game). On average, each subscriber spends 80 hours per month in WoW (Yee, 2006), so that 30 minutes costs roughly 8 euro cent. 
rarely catches other items like low-value swords, so that we talk in the result section about returned items, rather than fish).

Figure 1: Player Fishing in WoW

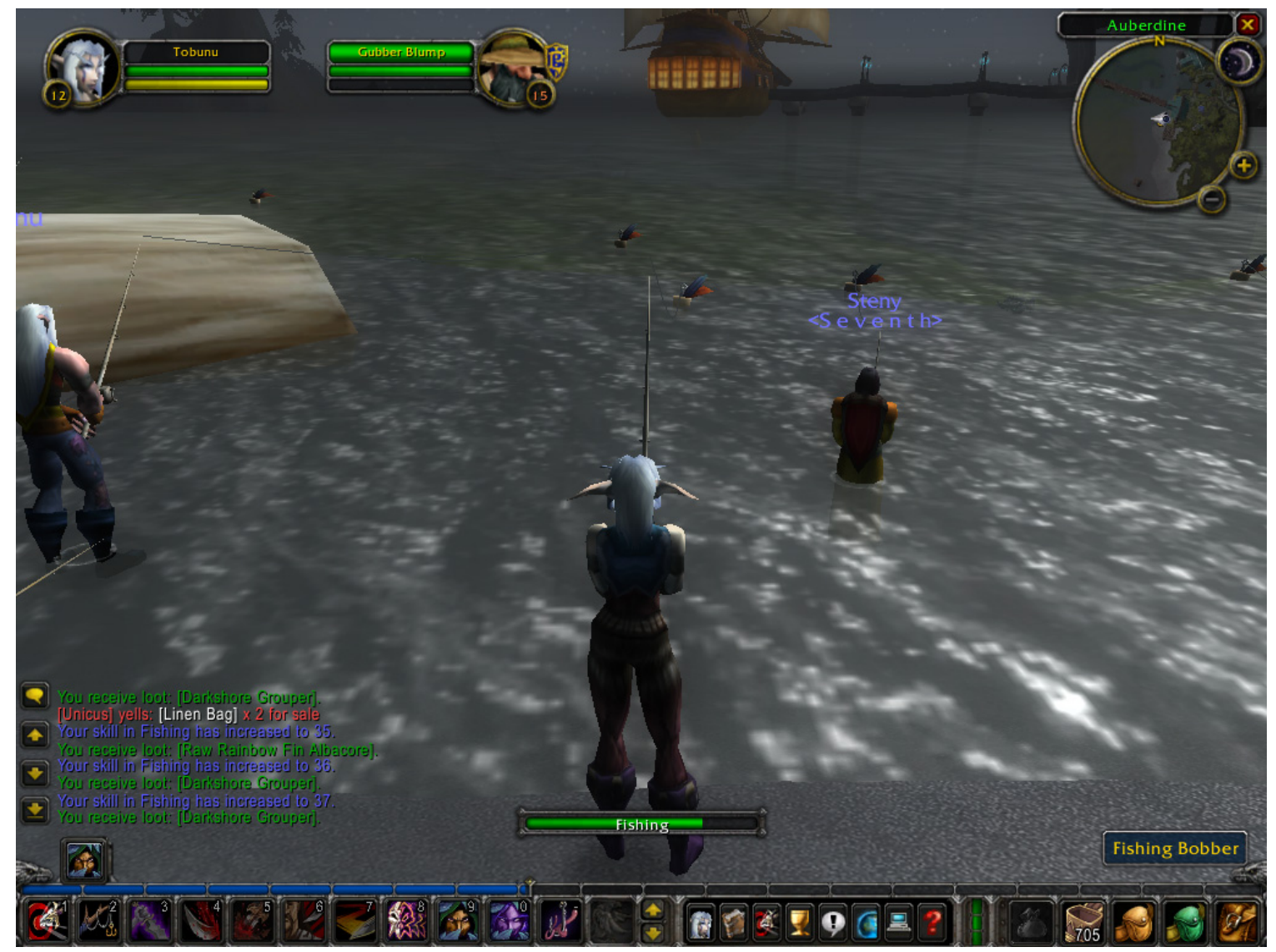

The probability of a fish taking the bait does not depend on how many fish are already caught at the particular pool. However, the probability that the agent catches the fish depends on some fishing experience, the "fishing skill", which increases with the number of catches already made. ${ }^{18}$ The fishing skill, which can be looked up for every character in an online database, ranges between 1 (freshman) and 375 (master). Some pools require a minimum skill, such that the probability to catch fish is zero for fishing skills lower than the minimum one; other pools have maximum skills, such that the probability to catch fish is one for fishing skills higher than the maximum one. Notice that the pool where we require participants to fish has no minimum, but a maximum skill level of $75 .{ }^{19}$ Therefore, the fishing skill tells us first the effort needed to catch a certain number of fish (so that the number of returned fish is a useful proxy for effort) and, second, the willingness of a player to fish in WoW. We cannot measure the disutility of fishing; however, the skill provides information about the willingness to perform the task previously.

18 Notice that fishing skill points are formally uncorrelated with the status level.

19 There is no market for fish from this particular pool (it is possible to identify in which pool fish are caught). Also, it is extremely unlikely that agents possess this particular fish from previous fishing; one can sell (but not buy) them to the local grocer. Hence, agents cannot - instead of providing effort - buy the fish, but have to work on their own, or subcontract to another player (although this seems very unlikely). 


\section{Hypotheses}

A field experiment in virtual worlds combines some of the advantages of field experiments and of laboratory experiments. It enables us to observe economic interactions socially embedded, while some of the controllability of laboratory experiments can be maintained. Particularly, we can analyze the variation of principals' status in a meaningful social environment. On the other hand, we will examine the effect of different wages on reciprocation rates controlling for task performance skills of agents.

Underpinning the importance of reciprocity for labor market relationships, there are several field experiments showing a positive wage-effort relation in gift exchange settings when wage increases are surprising (e.g., Gneezy \& List, 2006, Kube et al., 2007). However, in our setting, one could claim that offering generous rather than reasonable wages interests a different subset of agents. Presuming that agents refuse to shirk, generous wages may attract skilled as well as unskilled agents; in contrast, reasonable wages may attract only unskilled agents, since highly skilled agents have higher opportunity costs. Thus higher average effort under generous, rather than reasonable, wages is not per se a valid indicator for reciprocity, but needs to be controlled for agents' task skills. Therefore, we test

$\mathbf{H}_{1 \mathrm{a}}$ : Controlling for agents' task skills, the effort provision is higher in the 12 than in the 4 condition.

We want to stress that - unlike previous field experiments (e.g., Hennig-Schmidt, 2008) - shirking is a viable option in our setting; as we pay wages upfront, there is no need for further communication thereafter. The agents' effort decision does not depend on their expectations concerning the further progress of the employment relation once the effort has been provided. Therefore, the agents' decision is two-fold: first, the decision whether to provide effort and, second, the decision about how much effort to provide. Taking this into account, we will test also

$\mathbf{H}_{1 \mathrm{~b}}$ : Controlling for agents' task skills, the probability that agents provide effort is higher in the 12 than in the 4 condition.

With respect to the effect of principals' social status for agents' effort provision, the evidence is much less settled. ${ }^{20}$ People seem to seek for social status, since it functions as a signal for individual wealth (e.g., Bagwell \& Bernheim, 1996). Similar to reality, high social status levels in WoW are typically matches with high (in-game) wealth. Therefore, our manipulation of principals' social status attempts to affect agents' assessment of wage rates as it shapes their beliefs concerning principals' wealth. ${ }^{21}$ Laboratory experiments have shown that the acceptance of offers crucially depends on the set of alternatives from which the offer has been picked (Falk et al.,

20 A general survey of the economic literature of social status is given by Weiss \& Fershtman (1998).

21 Ball and Eckel (1998) and Ball et al. (2001) test experimentally the relation between status differentials and market interactions. In contrast to our setting, they introduce ad hoc a status hierarchy that offers little information about participants' wealth or prestige. 
2003). ${ }^{22}$ Similarly, one could argue that reasonable wage offers by a low status principal are kind, whereas reasonable wage offers by a high status principal are unkind, since the latter could have offered more. For our labor market relations, this claim suggests that agents perceive offers by low status principals more kindly than offers by high status principals, implying higher reciprocation rates in the former case than in the latter case. Therefore, we test

$\mathbf{H}_{2 \mathrm{a}}$ : The effort provision is higher in the $\mathrm{L}$ than in the $\mathrm{H}$ condition.

and

$\mathbf{H}_{2 \mathrm{~b}}$ : The probability that agents provide effort is higher in the $\mathrm{L}$ than in the $\mathrm{H}$ condition.

\section{Results}

Starting with our conjecture that different wage rates may attract different task skills, the data do not support this claim. There are no significant differences between skills under wage rate 12 (mean 56.7) and under wage rate 4 (mean 60.4). ${ }^{23}$ When analyzing the fishing skills for each treatment condition separately, we find one minor significant difference between $\mathrm{H} / 12$ and $\mathrm{L} / 12,{ }^{24}$ which, however, seems to be unsystematic since there are significant differences between $\mathrm{H} / 4$ and L/4. Mean differences are 72.9 under H/12, 63.1 under H/4, 40.6 under L/12, and 57.6 under the L/4 condition. Table 1 provides the detailed results for means and standard deviations for the skills.

Table 1: Means (Standard Deviation) of Task Skills

\begin{tabular}{|l|cc|}
\hline \multicolumn{1}{|c|}{ wage rate } & 12 & 4 \\
Status & & \\
\hline $\mathrm{H}$ & $72.9(73.7)$ & $63.1(68.9)$ \\
& {$[25]$} & {$[27]$} \\
$\mathrm{L}$ & $40.6(59.4)$ & $57.6(67.5)$ \\
& {$[26]$} & {$[25]$} \\
\hline
\end{tabular}

Note: Standard deviations in parentheses, number of observations in brackets.

Concerning effort provision, the means of returned items are shown in Figure 2. The vast majority of agents provided effort under all treatment conditions. Particularly, on average 80.3 items in the $\mathrm{H} / 12$ condition, 34.3 items in the $\mathrm{H} / 4$ condition, 63.4 items in the $\mathrm{L} / 12$ condition and 48.5 items in the $\mathrm{L} / 4$ condition were returned. The results suggest that a generous wage tentatively

22 Likewise, formal models of reciprocity (e.g., Rabin, 1993, Dufwenberg \& Kirchsteiger, 2004, Falk \& Fischbacher, 2006 or Cox et al., 2007) compare positive or negative deviations from a reference offer which crucially depends on the set of alternatives.

$23 p=0.57$ using a two-sided Mann-Whitney rank sum test.

$24 p=0.09$ using a two-sided Mann-Whitney rank sum test, for all other comparisons, we obtain $p>0.10$ using the same test method. 
increases the number of returned items. Only 4 players in the $H / 12,11$ in the $H / 4,2$ in the $L / 12$, and 5 in the L/4 condition sent nothing back. On the other hand, for low status, the difference between reasonable and generous wages is less pronounced. Using two-sided Mann-Whitney rank sum tests, we find only one significant difference among treatment conditions: a pair-wise comparison of the number of received items in the $\mathrm{H} / 12$ and in the $\mathrm{H} / 4$ condition yields $p=$ 0.003 ( $p=0.32$ for the comparison between the $\mathrm{L} / 12$ and the $\mathrm{L} / 4$ condition). Thus, it seems that higher wages increase the average number of returned items only in the high status condition.

Figure 2: Means of Returned Items

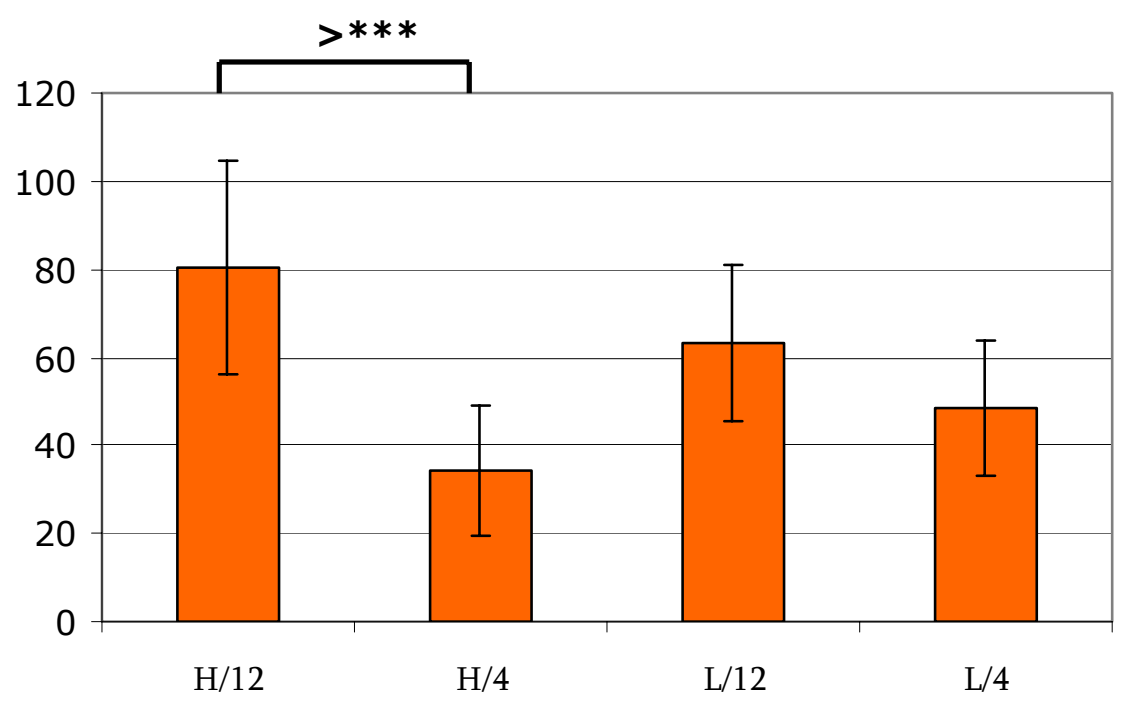

Note: Bars indicate $95 \%$-confidence intervals; ${ }^{* * *}$ indicate significant differences for $p<0.01$ using a two-sided Mann-Whitney rank sum test.

For a more detailed analysis of the effort provision controlling for wage rates, status and task skills, we estimate two regression models, one for the decision to provide effort or not, one for the extent to which effort is provided. ${ }^{25}$ Formally, let us denote with variable $e$ the number of returned items and the indicator variable $z$ with

$$
z=\left\{\begin{array}{c}
1 \quad \text { if } e>0 \\
0 \text { otherwise }
\end{array}\right.
$$

The dependent variable of the first probit estimation model is $z$ and tests for variables influencing the agents' decision to provide effort or not. The dependent variable of the second regression model is $e$ if $z=1$. Thus, the first model analysis will enable us to test $\mathbf{H}_{1 \mathrm{~b}}$ and $\mathbf{H}_{2 \mathrm{~b}}$, while the second estimation provides some evidence concerning $\mathbf{H}_{1 \mathrm{a}}$ and $\mathbf{H}_{2 \mathrm{a}}$. As independent variables, we introduce in both models the indicators $\mathrm{I}_{4}$ and $\mathrm{I}_{\mathrm{L}}$ as well as $\mathrm{I}_{4} \times \mathrm{I}_{\mathrm{L}}$ where $\mathrm{I}_{4}\left(\mathrm{I}_{\mathrm{L}}\right)$ equals 1 if the observation comes from the $4(\mathrm{~L})$ treatment and equals 0 otherwise. Thus the coefficient of $\mathrm{I}_{4}$ indicates differences along the wage dimension, while the coefficient of $\mathrm{I}_{\mathrm{L}}$ indicates differences

25 Notice that we also checked for a sample selection bias using Heckman's two-stage estimation model (Heckman, 1979). However, for various specifications of this model, the hypothesis that the error terms of the two stages are correlated has been robustly rejected. This suggests that there is no selection bias so that we proceed by analyzing the two decision models separately. 
along the status dimension; finally, the coefficient of $\mathrm{I}_{4} \times \mathrm{I}_{\mathrm{L}}$ indicates differences for the interaction between wage rates and status. Referring to $\mathbf{H}_{1 \mathrm{a}}$ and $\mathbf{H}_{1 \mathrm{~b}}$, we expect for $\mathrm{I}_{4}$ a negative coefficient, whereas according to $\mathbf{H}_{2 \mathrm{a}}$ and $\mathbf{H}_{2 \mathrm{~b}}$, the coefficient of $\mathrm{I}_{\mathrm{L}}$ is positive.

In addition to treatment differences, we will include agents' task performance skills, that is, the fishing skill. Recall that skill informs about the number of instances, agents performed the task so far. This means that skill informs us about the agents' acceptability of the task, implying higher acceptance of the task for higher skills. As a consequence, we will include skill in the first analysis of the decision to provide the effort or to shirk.

For the second analysis, that is, the amount of effort being provided, we have to consider that skill also informs about the probability with which the actual fish is caught. We mentioned earlier that the pool we require agents to fish has a maximum skill of 75 . Therefore, we normalize skill such that $s k i l l^{+}=\min \{$ skill/75, 1$\}$; consequently, including skill $^{+}$in the second regression will control for the effort needed to provide a certain amount of work.

Finally, we will also analyze the influence of relation between the agents' social status and the principal's status for both decisions. For this purpose, we define $\Delta$ level as the principal's social status level minus the agent's social status level. One could argue that agents of higher social status provide effort to principals in order to maintain their high reputation and prestige as they stick to their promises. Hence we expect to find a positive influence of the variable $\Delta$ level on both the probability and the extent of effort provision. On the other hand, high social status of agents is typically accompanied by high financial resources. This may suggest that high status agents evaluate the wage offer differently than low status agents. That is, they consider the gift less kindly since it does not substantially contribute to their wealth, suggesting a negative coefficient for $\Delta$ level. Table 2 summarizes the mean marginal effects of covariates for $z$, the corresponding probit regression model is provided in the appendix. Table 3 shows the coefficients (and consequently the marginal effects) of the linear regression model for $e$. 
Table 2: Mean marginal effect of the probit regression

\begin{tabular}{|l|c|}
\hline & dependent \\
independent & $z$ \\
\hline $\mathrm{I}_{4}$ & $-0.194^{* *}(0.098)$ \\
$\mathrm{I}_{\mathrm{L}}$ & $0.436^{* *}(0.177)$ \\
$\mathrm{I}_{4} \times \mathrm{I}_{\mathrm{L}}$ & $0.171 \quad(8.434)$ \\
skill & $0.002^{* * *}(0.001)$ \\
$\Delta$ level & $0.007^{* * *}(0.002)$ \\
\hline number of obs & 103 \\
Pseudo $\mathrm{R}^{2}$ & 0.17 \\
LR test (5) & $18.51^{* * *}$ \\
\hline
\end{tabular}

Note: ${ }^{* * *}$ significant on $<0.01,{ }^{* *}$ significant on $<0.05,{ }^{*}$ significant on $<0.1$; mean standard errors in parenthesis; number of obs denotes the number of observations, the fitness of the estimation is indicated by the Pseudo $R^{2}$, while the likelihood ration test for five variables tests the fitness of the model against the null model.

The results indicate that the skill significantly influences the agents' decision to provide effort. As expected, the higher the skill, the more likely it is for effort to be provided. However, the size of the marginal effect appears to be very small. Likewise, we find a small, but significantly negative effect for $\Delta$ level. For increasing social status of the agent, the probability with which he provides effort decreases. Thus, it seems that not the agent's reputation matters, but his own wealth while evaluating the wage offer.

Supporting $\mathbf{H}_{1 \mathrm{~b}}$, the marginal effect of $\mathrm{I}_{4}$ is significantly negative. Thus, lower wage rates significantly decrease the probability that agents provide effort. Yet, we find that this effect is overcompensated by the effect of having a low-status principal. Particularly, we find a significantly positive marginal effect of $\mathrm{I}_{\mathrm{L}}$. Notice that the absolute size is more than double the marginal effect of decreasing the wage rate, so that - keeping everything constant - the probability of effort provision even for a low status principal who offers wages of 4 is higher than for a high status principal offering a wage of 12 . Finally, the marginal effect for the interaction term as $\mathrm{I}_{4} \times \mathrm{I}_{\mathrm{L}}$ is insignificant. Confirming $\mathbf{H}_{2 \mathrm{~b}}$, these results indicate that low status principals receive per se some kind of bonus for the effort provision probability. 
Table 3: Marginal effect of the linear regression

\begin{tabular}{|l|c|}
\hline & dependent \\
independent & $e$ \\
\hline $\mathrm{I}_{4}$ & $-44.77^{* * *}(13.93)$ \\
$\mathrm{I}_{\mathrm{L}}$ & $-5.12 \quad(26.37)$ \\
$\mathrm{I}_{4} \times \mathrm{I}_{\mathrm{L}}$ & $25.63 \quad(18.13)$ \\
skill & $35.93^{* * *}(12.16)$ \\
$\Delta$ level & $0.099(0.41)$ \\
\hline number of obs & 103 \\
$\mathrm{R}^{2}$ & 0.22 \\
$\mathrm{~F}$ test $(5,97)$ & $5.82^{* * *}$ \\
\hline
\end{tabular}

Note: The constant term equals 58.69*** (19.09); ${ }^{* * *}$ significant on $<0.01,{ }^{* *}$ significant on $<0.05,{ }^{*}$ significant on <0.1; robust standard errors in parenthesis; number of obs denotes the number of observations, the fitness of the estimation is indicated by the $R^{2}$, while the $F$ test with five variables and 97 degrees of freedom tests the fitness of the model against the null model.

The results for the second model reveal the important influence of skill $^{+}$for the amount of effort provision. Opposing $\mathbf{H}_{2 a}$, the coefficients for $\mathrm{I}_{\mathrm{L}}$ and $\mathrm{I}_{4} \times \mathrm{I}_{\mathrm{L}}$ are insignificant, suggesting no systematic influence of the status on the amount of effort provision. Likewise, the data does indicate a systematic influence of $\Delta$ level. However, high wage rates indeed increase the amount of effort substantially. Supporting $\mathbf{H}_{1 \mathrm{a}}$, the coefficient of $\mathrm{I}_{4}$ is significantly negative. Thus there is evidence for gift exchange behavior with respect to the amount of effort, even if we control for skills. Increasing the gift upfront increases the amount of effort provided.

\section{Discussion}

The results of our gift exchange experiment contribute to the recent literature on employment relation "in the field" such that behavior of agents is strongly imposed by reciprocity in virtual worlds also. The majority of players in all treatment conditions reciprocate our wage offers by providing effort. Even if we control for the agents' skills, the variation of the wage rate influences both the probability that agents provide effort and the amount of effort provision.

With respect to the relation between principals' status and reciprocation rates, results are twofold. Concerning the amount of effort provided, there is no evidence for a systematic effect of social status. In contrast, the probability that effort is provided is severely influenced by the principal's status such that low status principals' have some advantages compared with high-status principals. It seems that the decision whether to provide effort or not (and the evaluation of the gift with respect to this issue) is done vis-à-vis agent's wealth and the expected wealth of the principal. Thus, the effort provision probability increases per se for low-status principals. Most 
striking, this effect even overcompensate the effect of a wage variation. This finding suggests that agents evaluate the wage offer with respect to their expectations concerning the principals' wealth - high status signals high wealth, while low status signals low wealth. Consequently, even reasonable wage offers by low-status principals are largely responded by effort provision. Along this result, we find that the probability of effort provision decreases in the agent's social status, indicating that the perception of wage offers also depends on their own wealth.

Overall, our field experiment shows the potential of online game communities for research on socially embedded human interaction. Experiments in virtual-world communities allow the analysis of economic activities in the field controlling for important factors like task performance skills and social embeddedness. Therefore, our field experiment will, hopefully, be the starting point for further research in virtual worlds, providing us with better understanding on the interdependencies between social structure and economic systems. 


\section{References}

Akerlof, G.A. (1982), Labor Contracts as Partial Gift Exchange, Quarterly Journal of Economics 97, 543-569.

Akerlof, G. A. \& J. L. Yellen (1990), The Fair Wage-Effort Hypothesis and Unemployment, Quarterly Journal of Economics 105, 255-283.

Al-Ubaydli, O., S. Andersen, U. Gneezy \& J. List (2006), For Love or Money? Testing NonPecuniary and Pecuniary Incentive Schemes in a Field Experiment, Working Paper.

Ajzen, I. (1991), The theory of planned behavior, Organizational Behavior and Human Decision Processes 50, 179-211.

Bagwell, L.S. \& B.D. Bernheim (1996), Veblen effects in a theory of conspicuous consumption, American Economic Review 86, 349-373.

Bainbridge, W.S. (2007), The scientific research potential of virtual worlds, Science 317, 472476.

Ball, S. \& C.C. Eckel (1998), The economic value of status, Journal of Socio-Economics 27, 495514.

Ball, S., C.C. Eckel, P.J. Grossman \& W. Zame (2001), Status in markets, Quarterly Journal of Economics 155, 161-181.

Blizzard Cooperation (2008), World of Warcraft reaches new milestone: 10 million subscribers, Press realise, 01/22/2008.

Bloomfield, R.J. (2007). Worlds for Study: Invitation - Virtual Worlds for Studying Real-World Business (and Law, and Politics, and Sociology, and....), Working Paper, Johnson Graduate School of Management, Cornell University.

Castranova, E. (2001), Virtual worlds: A first-hand account of market and society on the cyberian frontier, CESifo Working Paper Series 618.

Castranova, E. (2008), A test of the law of demand in a virtual world: Exploring the Petri dish approach to Social Science, CESifo Working Paper Series 2355.

Chesney, T., S.-H. Chuah \& R. Hoffmann (2007), Virtual world experimentation: An exploratory study, University of Nottingham Discussion Paper 2007-14.

Cox, J. C., D. Friedman \& S. Gjerstad (2007), A Tractable Model of Reciprocity and Fairness, Games and Economic Behavior 59, 17-45.

Fahr, R. \& B. Irlenbusch (2000), Fairness as a constraint on trust and reciprocity, Economics Letters 66, 275-282. 
Falk, A. (2007), Gift exchange in the field, Econometrica 75, 1501-1511.

Falk, A., E. Fehr, \& U. Fischbacher (2003), On the nature of fair behaviour, Economic Inquiry 41, 20-26.

Falk, A. \& U. Fischbacher (2006), A theory of reciprocity, Games and Economic Behavior 54, $293-315$.

Falk, A. \& A. Ichino (2006), Clean evidence on peer effects, Journal of Labor Economics 24, $39-57$.

Fehr, E. \& S. Gächter (2000), Cooperation and punishment in public goods experiments, American Economic Review 99, 980-994.

Fehr, E. \& F. Götte (2008), Do workers work more if wages are high? Evidence from a randomized field experiment, American Economic Review 97, 298-317.

Fehr, E., G. Kirchsteiger \& A. Riedl (1993), Does fairness prevent market clearing? An experimental investigation, Quarterly Journal of Economics 108, 437-460.

Fehr, E. \& K.M. Schmidt (2006), The economics of fairness, reciprocity and altruism - Experimental evidence and new theories. In: Kolm, S.-C. \& J.M, Ythier (eds.), Handbook of the Economics of Giving, Altruism and Reciprocity, Volume I, Amsterdam: Elsevier, 615-694.

Fiedler, M. \& E. Haruvy \& S. Li (2008), Choice between trust games with different multipliers and social distance: A virtual world experiment, mimeo.

Fischbacher, U., S. Gächter \& E. Fehr (2001), Are people conditionally cooperative? Evidence from a public goods experiment, Economics Letters 71, 397-404.

Gintis, H. (2000), Strong reciprocity and human sociality, Journal of Theoretical Biology 206, 169-179.

Gneezy, U. (2003), Do high wages lead to high profits? An experimental study of reciprocity using real effort, Working Paper, Graduate School of Business, University of Chicago.

Gneezy, U. \& J.A. List (2006), Putting behavioral economics to work: Testing for gift exchange in labor markets using field experiments, Econometrica 74, 1365-1384.

Gouldner, A.W. (1960), The norm of reciprocity: A preliminary statement, American Sociological Review 25, 161-178.

Granovetter, M. (2005), The impact of social structure on economic outcomes, Journal of Economic Perspectives 19, 33-50.

Güth, W., R. Schmittberger \& B. Schwarze (1982), An experimental analysis of ultimatum bargaining, Journal of Economic Behavior \& Organization 3, 367-388. 
Harrison, G. \& J.A. List (2004), Field experiments, Journal of Economic Literature 42, 10091055.

Heckman, J.J. (1979), Sample bias as a specification error, Econometrica 47, 153-162.

Hennig-Schmidt, H., B. Rockenbach \& A. Sadrieh (2008), In search of workers' real effort reciprocity - A field and a laboratory experiment, The Journal of the European Economic Association, forthcoming.

Isaac, R.M., K.F. McCue \& C. Plott (1985), Public good provision in an experimental environment, Journal of Public Economics 26, 51-74.

Kube, S., M.A. Maréchal \& C. Puppe (2006), Putting reciprocity to work - Positive versus negative responses in the field, Working Paper 2006-27, University of St. Gallen.

Rabin, M. (1993), Incorporating fairness into game theory and economics, American Economic Review 83, 1281-1302.

van Dijk, F., J. Sonnemans \& F. van Winden (2001). Incentive systems in a real effort experiment, European Economic Review 45, 187-214.

Weiss, Y. \& C. Fershtman (1998), Social status and economic performance: A survey, European Economic Review 42, 801-820.

Williams, D., N. Ducheneaut, L. Xiong, Y. Zhang, N. Yee \& E. Nickell (2006), From tree house to barracks: The social life of guilds in World of Warcraft, Games and Culture 1, 338-361.

Yee, N. (2006), The demographics, motivations and derived experiences of users of massivelymultiuser online graphical environments, Teleoperators and Virtual Environments 15, 309329. 


\section{Appendix: The probit estimation model}

\begin{tabular}{|c|c|}
\hline $\begin{array}{ll} & \text { dependent } \\
\text { independent } & \\
\end{array}$ & $z$ \\
\hline $\mathrm{I}_{4}$ & $-0.805^{*} \quad(0.412)$ \\
\hline$I_{L}$ & $1.819^{* *}(0.822)$ \\
\hline$I_{4} \times I_{L}$ & $0.204 \quad(0.64)$ \\
\hline skill & $0.008^{* * *}(0.003)$ \\
\hline$\Delta$ level & $0.028^{*} \quad(0.014)$ \\
\hline constant & $0.113 \quad(0.435)$ \\
\hline number of obs & 103 \\
\hline logLik & -44.17 \\
\hline
\end{tabular}

Note: ${ }^{* * *}$ significant on $<0.01,{ }^{* *}$ significant on $<0.05,{ }^{*}$ significant on $<0.1$; standard errors in parenthesis; number of obs denotes the number of observations; logLik denotes the log likelihood of the model. 